\title{
ESTUDIOS TRANSAREALES Y ESTUDIOS TRANSANDINOS
}

\author{
POR \\ OtTMAR ETte \\ Universität Potsdam
}

\section{COREOGRAFÍAS TRANSANDINAS}

Al interior de una de las mezquitas más fastuosas del mundo islámico, dentro de la cual se construyó, con impetuoso orgullo y triunfal violencia, una impresionante catedral cristiana, fue que en el año 1613, un tal Don Gómez Suárez de Figueroa, adquirió la capilla de la cual aquí hablaremos brevemente. Al morir en 1616, este noble español nacido en los Andes sudamericanos, hizo que lo sepultaran en esta capilla, cuya inscripción aún hoy nos refiere al nombre bajo el cual este hombre goza hasta la actualidad de gran fama:

El Inca Garcilaso de la Vega, varón insigne, digno de perpetua memoria. Ilustre en sangre. Perito en letras. Valiente en armas. Hijo de Garcilaso de la Vega. De las Casas de los duques de Feria e Infantado y de Elisabeth Palla, hermana de Huayna Capac, último emperador de las Indias. Comentó La Florida. Tradujo a León Hebreo y compuso los Comentarios Reales. Vivió en Córdoba con mucha religión. Murió ejemplar. Dotó esta capilla. Enterróse en ella. Vinculó sus bienes al sufragio de las Animas del Purgatorio. [Son Patronos perpetuos los señores Deán y Cabildo de esta Santa Iglesia. Falleció a 22 de abril de 1616. Rueguen a Dios por su ánima.] $]^{1}$

El varón insigne que yace aquí sepulto y que mandó a adornar la artística reja a la entrada de su capilla con el blasón heráldico de su procedencia inca, no es otro que el autor de esa gran obra literaria que aquí es mencionada junto a sus labores de traducción inter y transcultural (ver López Baralt, Jakfalvi-Leiva y Zamora), cuyo resultado más famoso son las traducciones de los Dialoghi del poeta y médico Leone Ebreo, también conocido como Leo Hebraeus alias Jehuda ben Isaak Abravanel. De esta forma, en un espacio breve y conciso, hallamos en el monumento funerario del Inca Garcilaso de la Vega la presencia de huellas incaicas, islámicas, cristianas y judaicas, referencias al Perú y La Florida, Italia y España, al último emperador Inca y a las ánimas del Purgatorio,

\footnotetext{
1 Una reprodución parcial de la inscripción puede consultarse en Mataix.
} 
a los representantes de la Iglesia católica y de los poderes terrenales, a las insignias de las armas y las letras. Un ejercicio de las letras verdaderamente incansable, que siempre estuvo dedicado -y una última vez más en el texto esculpido sobre la piedra- a sopesar los vectores de una vida, que, como ninguna otra, buscó siempre pensar y relacionar interdependientemente al viejo y al nuevo mundo en todas sus diferentes tradiciones.

Los biografemas enlistados con orgullo en esta inscripción en la entrada a la Capilla de las Ánimas con sus referencias genealógicas al padre español-el conquistador Sebastián Garcilaso de la Vega-, tanto como a la madre inca -la ñusta o princesa Isabel Chimpu Ocllo, la sobrina del Inca Túpac Yupanqui y nieta del Inca Huayna Cápac- oponen una decidida resistencia a todos aquellos esfuerzos por reducir al Inca Garcilaso de la Vega a una única procedencia cultural. Por lo mismo y bajo el contexto de reflexión transareal y transandina aquí propuesto, de lo que se trata es de no regresar a la canónica descripción de este hombre nacido en el Cuzco en 1539 como el "primer mestizo de personalidad y ascendencia universales que parió América" (Sánchez 353), sino enfrentar el hecho de que incluso en el lugar de su último reposo se (dis)tienden los vectores de una vida que se encontraba siempre en nuevos movimientos dentro de un campo de fuerzas entre las religiones, entre los imperios, entre las culturas y entre las lenguas (ver Fritz).

El Inca Garcilaso de la Vega, quien pasara las primeras dos décadas de su vida en el Cuzco, su ciudad natal, y quien luego, después de la muerte de su padre en el año de 1560, viviera cincuenta y seis años en la andaluza Montilla y en Córdoba (Lavalle 135-136 y Hilton 7-10); este Inca Garcilaso de la Vega, ya en el "Proemio al lector" antepuesto a sus famosos y sumamente influyentes Comentarios reales (ver González, Acosta, Iniesta Cámara y Montiel), ofrece a nuestros ojos este vital campo de fuerzas. En éste, se hace ostensible tanto su orgullo sobre la doble ascendencia como su inteligente evaluación de las relaciones de fuerzas, dentro de las cuales una crítica a los historiadores españoles no debía ser llevada demasiado lejos. Su argumentación, en consecuencia, es impulsada a la vez por la precaución y la tenacidad:

Aunque ha habido españoles curiosos que han escrito las repúblicas del Nuevo Mundo, como la de México y la del Perú, y la de otros reinos de aquella gentilidad, no ha sido con la relación entera que de ellos se pudiera dar, que lo he notado particularmente en las cosas que del Perú he visto escritas, de las cuales, como natural de la ciudad del Cuzco, que fue otra Roma en aquel imperio, tengo más larga y clara noticia que la que hasta ahora los escritores han dado. Verdad es que tocan muchas cosas de las muy grandes que aquella república tuvo: pero escríbenlas tan cortamente, que aun las muy notorias para mí (de la manera que las dicen) las entiendo mal. Por lo cual, forzado del amor natural de la patria, me ofrecí al trabajo de escribir estos Comentarios, donde clara y distintamente se verán las cosas que en aquella república había antes de los españoles, así en los ritos de su vana religión, como en el gobierno que en paz y en guerra sus reyes tuvieron, y todo lo demás que de aquellos indios se puede decir, desde lo más ínfimo del ejercicio de los vasallos, hasta lo más alto de la corona real.

Revista Iberoamericana, Vol. LXXXI, Núm. 253, Octubre-Diciembre 2015, 1115-1137 
Escribimos solamente del imperio de los Incas, sin entrar en otras monarquías, porque no tengo la noticia de ellas que de ésta. En el discurso de la historia protestamos la verdad de ella, y que no diremos cosa grande, que no sea autorizándola con los mismos historiadores españoles que la tocaron en parte o en todo: que mi intención no es contradecirles, sino servirles de comento y glosa, y de intérprete en muchos vocablos indios que como extranjeros en aquella lengua interpretaron fuera de la propiedad de ella, según que largamente se verá en el discurso de la Historia, la cual ofrezco a la piedad del que la leyere, no con pretensión de otro interés más que de servir a la república cristiana, para que se den gracias a Nuestro Señor Jesucristo y a la Virgen María su Madre, por cuyos méritos e intercesión se dignó la Eterna Majestad de sacar del abismo de la idolatría tantas y tan grandes naciones, y reducirlas al gremio de su Iglesia católica romana, Madre y Señora nuestra. Espero que se recibirá con la misma intención que yo le ofrezco, porque es la correspondencia que mi voluntad merece, aunque la obra no la merezca. Otros dos libros se quedan escribiendo de los sucesos que entre los españoles en aquella mi tierra pasaron, hasta el año de 1560 que yo salí de ella: deseamos verlos ya acabados, para hacer de ellos la misma ofrenda que de éstos. Nuestro Señor, etc. (Garcilaso I, 5-6)

Si reproducimos aquí el "Proemio" en su totalidad, esto se debe a que en él se despliega de forma brevísima una posición móvil y en constante cambio del yo y su relación con los temas representados -y esto en una complejidad que no podría ser descrita adecuadamente mediante ninguna historia de las transferencias, mediante ninguna Histoire croisée (ver Werner y Zimmermann). ${ }^{2}$ Los numerosos biografemas de esta figura del yo intercalados en el texto permiten re-trazar no sólo un camino vital que lleva de América hacia Europa, sino mucho más las oscilaciones que condicionan y hacen posible una presentación poliperspectivista de los objetos y temas.

A través del constante vínculo entre escritura y vida, el Inca Garcilaso de la Vega es capaz de re-presentar la historia que él propone desde la perspectiva de una historia vivenciada y vivida, de tal forma que el propio saber de la vida (Lebenswissen) de la figura del yo entra en íntima relación con formas del saber y formas de representación abstractas, aunque extraídas de un conocimiento empírico y directo de los objetos y temas. En consecuencia, lo que aquí se pone en juego es mucho más que el curriculum vitae "transandino" de un eminente autor. Los Comentarios reales no pueden desprenderse, no pueden abstraerse, del saber sobre la vida transcultural de este yo escenificado.

Almismo tiempo, este saber de la vida es un saber(del) sobrevivir(Überlebenswissen): el autor escenificado se sabe dentro de una estructura de poder en España, la que si bien, en cuanto descendiente de una cierta nobleza, le ha abierto sus puertas, también lo amenaza con una perspectiva de mundo unilateral y con una ortodoxia inquisitorial,

2 Para otras perspectivas de la historia de las transferencias como la Connected History, Shared History o Entangled History véase Subrahmanyam, Gruzinski y Randeria.

Revista Iberoamericana, Vol. LXXXI, Núm. 253, Octubre-Diciembre 2015, 1115-1137 
cuyo monolingüismo se hace perfectamente visible en la discursividad del proemio. Fundamento de este saber (del) sobrevivir es la inscripción absoluta de este yo en un contexto histórico-sagrado, en la medida en que sólo ha sido la santa religión de la Iglesia católica romana la que ha salvado a tantas y tan grandes naciones y a sus habitantes $-\mathrm{y}$ con ello también al yo mismo- del abismo de la idolatría (Brading 6-7 y MacCormack, "Religion" 340 ss).

Esta adhesión absoluta a esta historia sagrada cristiana, que también se plasmó en la compra de la Capilla de las Animas dentro de la mezquita de Córdoba transformada en catedral cristiana, hace posible al mismo tiempo una serie de movimientos entre España y "aquella mi tierra", entre "los españoles" y la población indígena del Perú, que no se manifiesta en una posición intermedia, sino que se expresa en constantes figuras móviles y de movimientos. No es casualidad que ya el nombre de la Capilla de las Animas remita a las ánimas en el Purgatorio y con ello a ese cristiano espacio de movimientos y mociones, situado "entre" los puntos fijos del cielo y el infierno. La oscilación entre el mundo español, dentro del cual el yo se mueve desde hace varias décadas y en el que se sitúan también los explícitamente interpelados lectores del texto presentado, y aquel "nuevo mundo", del cual el Perú forma parte, permite hablar de un "amor natural de la patria", en el cual el objeto de este amor es considerado simultáneamente desde diversas perspectivas: este amor a la patria se puede referir tanto al virreinato del Perú como al imperio prehispánico de los Incas, sin embargo también a España, la que en cuanto patria del padre ha creado un imperio transatlántico mediante la conquista del Tawantinsuyo.

Si el saber de la vida del Inca Garcilaso se expresa en un saber (del) sobrevivir orquestado literariamente y con mucha inteligencia, este saber (del) sobrevivir, marcado por los sólidos fundamentos de una adhesión a la Iglesia católica romana precisamente en la época de la herejía protestante y de las guerras en contra de los levantamientos en las Alpujarras, permite reconocer también en el "Proemio al lector" del Inca Garcilaso, el esbozo de un saber (del) convivir, que acompaña a las formas expresivas de esta escritura designada comúnmente como "mestiza". Sin embargo, aquí no se trata de marcar un posicionamiento sólido como el de mestizo dentro de la sociedad imperante, sino mucho más de la validación de una procedencia al menos doble, que no sólo adquiere expresión en el sobrenombre de "el Inca", como en tantos otros de los ya mencionados biografemas, sino que es expresada activamente, es llevada a la expresión.

El saber-del-con-vivir (ZusammenLebensWissen), proyectado y desplegado por el Inca Garcilaso de la Vega, insiste pues en una posición de movimientos, dentro de la que la figura del yo se pone en escena como una figura móvil. No sólo una lengua, como es el caso de los autores españoles, sino un multilingüismo es lo que representa la condición previa para poder realizar las distintas labores de traducción lingüística y cultural (ver Scharlau). No sólo una ascendencia única, sino complejas procedencias constituyen la condición previa para poder comprender y representar literaria y simultáneamente las más diversas sociedades y "repúblicas", desde sus élites hasta el pueblo, desde el interior y

Revista Iberoamericana, Vol. LXXXI, Núm. 253, Octubre-Diciembre 2015, 1115-1137 
desde el exterior, tanto como en un movimiento transversal. El convivir aquí proyectado se basa, entonces, en la capacidad de pensar simultáneamente en diversas lógicas - y por supuesto, también en la capacidad de vivirlas. ${ }^{3}$

Esto se evidencia asimismo en la designación del propio lugar de nacimiento, "la ciudad del Cuzco, que fue otra Roma en aquel imperio”, con la cual el Cuzco prehispánico es puesto al mismo nivel que Roma, la "ciudad eterna" (ver MacCormack, "The Incas" y On the wings). El procedimiento de esta iluminación interdependiente de ambas ciudades remite no sólo a su importancia religiosa, sino además presenta la relación entre el imperio de los Incas con la antigüedad romana y, en consecuencia, entre la antigüedad del viejo mundo con la del nuevo. La pretensión sobre la dignidad histórica vinculada a esto, hace surgir, más allá de la comparación y de la transferencia, un movimiento de oscilación constante, en el que la procedencia propia aparece en su diferencia bajo la doble luz de la Roma antigua y contemporánea, sin que esto signifique su conversión en una otredad absoluta. En cuanto espacio urbano, Cuzco no se vuelve un espacio de lo propio $o$ de lo otro, sino un espacio móvily de movimientos de lo propio en cuanto otro y simultáneamente de lo otro en cuanto propio: en su movimiento, el lexema otra no puede detenerse nunca más. No está por una identidad sólida ni por una alteridad fija.

La alta vectoricidad de este concepto es comprobable en todas las coordenadas espaciales que remiten a la patria, a mi tierra, al lugar de la "propia" procedencia: es decir, a territorialidades que son enunciadas siempre en su vectoricidad. "Mi tierra" y "patria" se vuelven así expresiones que no marcan lugares fijos, sino espacios de movimiento como partes de un paisaje transatlántico, que sin lugar a dudas podemos denominar también como transandino.

Todo aquel que se aproxime a este paisaje urbano de una "otra Roma" proyectado por el Inca Garcilaso, no puede concebir este cityscape desde la perspectiva de una lógica única (Appadurai 33). Y a diferencia de los escritos de los autores e historiadores españoles que el Inca Garcilaso clara aunque cuidadosamente critica, todos los objetos y temas son concebidos desde diversas lógicas y a partir del movimiento mismo, y nunca constatados estáticamente. Así se despliega desde la viviencia, un saber (del) vivenciar (ErlebensWissen) que como saber de la vida del Inca Garcilaso tiene en cuenta no las fronteras, sino el desplazamiento de fronteras, no los territorios, sino las imágenes móviles y en movimiento de estos places y spaces (ver Mitchell vii-xii).

A partir de este nuevo y altamente móvil "paisaje de la teoría” (Ette, Literatur 53138) surge una innovadora comprensión de la historia, que se esfuerza por reinterpretar la historia dominada hasta el momento por los historiadores españoles e incorporar en la escritura de la historia misma una manera de ver poliperspectiva. Las fronteras

3 Sobre la simultaneidad no excluyente y no sintética de los opuestos, ver la lectura de El pez de oro de Gamaliel Churata, realizada por Meritxell Hernando Marsal en su contribución a este volumen.

Revista Iberoamericana, Vol. LXXXI, Núm. 253, Octubre-Diciembre 2015, 1115-1137 
histórico-sagradas de una historiografía tal resultan evidentes bajo un contexto marcado por la Inquisición española, sin embargo remiten prospectivamente a las posibilidades de un proyecto histórico polifónico, que no se deja acorralar por la simple oposición entre Occidente y el resto. ${ }^{4}$

Entre el imperio romano y el imperio inca no irrumpe precisamente la comparación acotadora, sino aparece un común y comunitario paisaje de comprensión transandino, en el cual los biografemas del autor se registran en la forma de trayectorias. La escritura desde España no se corresponde con una manera de ver unilateral realizada únicamente desde España. No podemos dejarnos engañar por las reverencias retóricas de Garcilaso ante las autoridades españolas, que forman parte de su saber (del) sobrevivir: ya en los Comentarios reales se perfila una nueva y poliperspectivística escritura de la historia como respuesta a la primera fase de la globalización acelerada. ${ }^{5}$

Si estos tardíos Comentarios reales - publicada su primera parte por primera vez en Lisboa en 1609- testimonian el alto y creciente interés que tuvo el Inca Garcilaso de la Vega por la dimensión inca de sus procedencias a lo largo de su vida, también hay que decir que surgieron precisamente en el momento en que empieza a consolidarse, trozo a trozo, un Virreinato del Perú que había sido largo tiempo sacudido por enfrentamientos y guerras civiles; lo que tal vez hace evidente una condición decisiva. Precisamente a través de la distancia espacial y temporal del Cuzco de su juventud, es que la vida de Garcilaso, que en sí misma se debe a la expansión bélica de los españoles en la primera fase de la globalización acelerada, adquiere aquella intuición y visión en las posibilidades e inevitable necesidad de desarrollar una imagen histórica poliperspectivística.

Del inmenso campo transandino que inauguran los Comentarios reales, desentrañaremos en este lugar sólo un punto más. Un pasaje del capítulo diecinueve de esta iridiscente obra ilustra los esfuerzos del Inca por situarse de cierta forma en el móvil punto nodal del flujo de informaciones, para desarrollar a partir de esta móvil posición una visión propia de América. Una vez más, tratando tanto de la legitimación de sus propios saberes, como de la superioridad de la propia posición móvil y de movimientos, aclara el autor de los Comentarios reales de una manera impresionante, cómo ha reunido las informaciones para su visión (y versión) de la historia:

En suma, digo que me dieron noticia de todo lo que tuvieron en su república; que si entonces lo escribiera, fuera más copiosa esta historia. Demás de habérmelo dicho los indios, alcancé y vi por mis ojos mucha parte de aquella idolatría, sus fiestas y supersticiones, que aún en mis tiempos, hasta los doce o trece años de mi edad, no se habían acabado del todo. Yo nací ocho años después que los españoles ganaron mi tierra, y como lo he dicho, me crié en ella hasta los veinte años, y así vi muchas cosas

Como se aprecia en los libros de Niall Ferguson o Samuel P. Huntington.

Sobre las diferentes cuatro fases de aceleración de la globalización, véase Ette (TransArea 8-26).

Revista Iberoamericana, Vol. LXXXI, Núm. 253, Octubre-Diciembre 2015, 1115-1137 
de las que hacían los indios en aquella su gentilidad, las cuales contaré, diciendo que las vi. Sin la relación que mis parientes me dieron de las cosas dichas y sin lo que yo vi, he habido otras muchas relaciones de las conquistas y hechos de aquellos reyes; porque luego que propuse escribir esta historia, escribí a los condiscípulos de escuela y gramática, encargándoles que cada uno me ayudase con la relación que pudiese haber de las particulares conquistas que los Incas hicieron de las provincias de sus madres; porque cada provincia tiene sus cuentas y nudos con sus historias, anales y la tradición dellas; y por esto retiene mejor lo que en ella pasó que lo que pasó en la ajena. (Garcilaso I, 45)

A partir de este posicionamiento anímico de la figura del yo desde dentro y desde fuera con respecto a los indios y con respecto a los españoles, el autor despliega el constante movimiento de la recolección de información desde todos lados. En éste, para la escritura de su historia en España, juegan un rol fundamental las relaciones orales de sus familiares -el acceso al saber sobre el gobierno que poseían las élites incas-, la remisión a la escritura de la historia española de su tiempo, las informaciones comprendidas en narraciones orales y en escritura no alfabética (nudos), ${ }^{6}$ así como las noticias de aquellos condiscípulos de escuela y sus contemporáneos, a los cuales el Inca Garcilaso les escribía en cuanto fuentes de información y corresponsales en la distancia.

Junto a los diferentes caminos de transmisión y a las diversas formas de oralidad y escritura, se suma por supuesto la siempre destacada condición testimonial, que agrega a la dimensión de lo oído la, tal vez más importante, dimensión de lo visto y lo vivido. La gran riqueza en observaciones sobre la vida cotidiana que caracteriza a los escritos del Inca Garcilaso, aunque sobre todo a sus Comentarios reales, transmite a la escritura de este autor una medida máxima de vivacidad, ya que sus textos una y otra vez se refieren a lo vivenciado y lo vivido.

Los flujos de información expuestos aquí de forma concisa y breve hacen surgir un paisaje transareal de un saber, que no puede reducirse a ningún tipo de territorialidad estática. Precisamente porque los biografemas de la figura del yo remiten a los dos lados del Atlántico - tanto a los Andes como a Andalucía- con igual necesidad se encuentran también aquílas circulaciones de un saber que inaugura espacios de reflexión y movimientos transandinos. Lo autobiográfico se anuda inextricablemente con lo historiográfico -la escritura de la historia del Perú y la escritura de la propia vida se entrelazan de manera fundamental y despliegan, a partir del movimiento transareal, un espacio transandino, cuya construcción sería por cierto imposible sin estas coreografías. En el medio de la escritura surgen miradas internas del mundo andino, las que por otra parte hubieran sido

6 Con respecto a la oralidad en la obra del Inca Garcilaso véase, entre otros, el texto de Song No y el ya clásico estudio de Mazzotti; sobre los khipus y su presencia tanto en el Inca Garcilaso como en otras crónicas de indias, consúltese Sempat y Urton.

Revista Iberoamericana, Vol. LXXXI, Núm. 253, Octubre-Diciembre 2015, 1115-1137 
impensables sin la contrastiva posición externa, situada precisamente en un campo de tensiones junto a las culturas árabe y judía. Oscilaciones que en la escritura trasladan todas las posiciones a incesantes movimientos. ${ }^{7}$ El Inca Garcilaso de la Vega no podría haber escogido un mejor lugar de movimientos para su último lugar de descanso.

\section{HistoRias TRANSAREALES DE LA GLOBALIZACIÓN}

Lo que la escritura del Inca Garcilaso de la Vega nos hace absolutamente evidente es la necesidad que tenemos hoy de desarrollar una epistemología que no sólo sea capaz de integrar críticamente los complejos saberes de la vida, del sobrevivir, del convivir, sino además que aspire a la convivencia en diferencia y en paz. Una epistemología que sin una dinámica transareal y sin las literaturas del mundo resulta impensable. Porque la comprensión que tienen las literaturas del mundo de la globalización como un complejo proceso de longue durée, estructurado y en cierto modo ritmado por distintas fases de aceleración, no recurre únicamente a las formas y normas del saber disciplinarias y disciplinantes que se han desarrollado dentro de una tradición científica muy marcada por Europa -aunque de ninguna manera hayan surgido exclusivamente en Europa- y que han sido globalmente irradiadas en distintos impulsos. En los teórico-culturalmente dispuestos Trans Area Studies no se trata de lograr una representación lo más exacta posible de la realidad global, sino simultáneamente (y quizás mucho más) de la comprensión y presentación, lo más polilógicamente posible, de las realidades vividas. Más acá y más allá de las dimensiones de la comparación, transferencia y entrelazamiento (ver Werner y Zimmermann), se trata de una constelación de saberes y ciencias transareales en torno a una poética del movimiento, que sea capaz de considerar tanto transdisciplinaria como poliperspectivamente procesos "fundamentalmente complejos" (Cramer 223) en sus múltiples y contradictorios contextos de vida. Estos estudios deben permanecer conscientes ante la visión de que un sistema fundamentalmente complejo siempre vincula tres aspectos: una prognosis limitada, una irreversibilidad fundamental de todos los procesos y el hecho de que el todo jamás puede pensarse como la suma de las partes. Las literaturas del mundo se dejan comprender así como un correctivo, que ante las disciplinas y sus saberes alcanzados, siempre sostiene críticamente un espejo que siendo reflexivo, se muestra a su vez quebrado en múltiples y diversos puntos de vista.

Si quisiéramos distinguir - por supuesto de forma muy esquemática- una ciencia transareal en el sentido de una unión transdisciplinaria de los campos de investigación más diversos de las propuestas comparatistas tradicionales, podríamos decir que en el caso de estas últimas se comparan y en cierto modo se confrontan estáticamente las

Estas dinámicas generadas por movimientos transareales desde el exterior y juegos entre la observación histórica y la autobiografía pueden apreciarse de una manera muy clara en la lectura que ofrece Roger Friedlein de El Bernardo de Bernardo de Balbuena en este volumen.

Revista Iberoamericana, Vol. LXXXI, Núm. 253, Octubre-Diciembre 2015, 1115-1137 
políticas, sociedades, economías y producciones simbólicas de diversos países, mientras que una ciencia transareal apunta más hacia los movimientos, intercambios y procesos de transformaciones mutuas. A los estudios transareales le interesan más los caminos que los espacios, los desplazamientos de fronteras que los trazados de fronteras, las relaciones y comunicaciones más que los territorios. Nuestra era de redes e interconexiones requiere conceptos científicos móviles y relacionales, transdisciplinarios y transareales y conceptualizaciones orientadas hacia el movimiento, que en los estudios literarios no pueden desarrollarse a partir de unas pocas literaturas nacionales (sean estas europeas, americanas, africanas, etc.). No se trata de una conceptualización de estructuras de red $^{8}$ a escala global que son solamente móviles, sino que estas estructuras de red son a la vez vívidas/vividas.

Ante el trasfondo de este cambio de perspectiva histórico-móvil, la multiplicación vectorial de lógicas y puntos de vista, así como el instrumental de conceptos ya descrito en otra parte (Ette, TransArea 1-49), es que se comprenden con claridad las enormes posibilidades y alcances de los estudios transareales. Teniendo en mente la primera aproximación de la mano del Inca Garcilaso, aquí emprenderemos una segunda tras los pasos de Mario Vargas Llosa.

En El sueño del celta, libro publicado el año 2010, poco después de que el escritor recibiera el premio Nobel, se nos presenta una estructuración literaria, altamente reflexiva desde perspectivas técnico-narrativas, socioeconómicas e histórico-globales, que entrelaza tres continentes -Europa, África y América- de manera tan profunda, que estos tres "mundos" ya no pueden pensarse por separado: son componentes de un sistema interdependiente, cuyo saber sobre el dominio tanto como el ejercicio de la violencia se encuentran asimétricamente repartidos sobre la tierra. Si algún lector peruano o hispanohablante, aunque también alguno de aquellos que en otras partes del globo han tenido acceso a la obra mediante una velocísima traducción, si alguno de estos lectores, digo, se quisiera plantear de entrada la pregunta de qué es lo que vincula a estas tres áreas en el próspero Fin de siècle antes del estallido de la primera Guerra Mundial, esta novela separada en las partes "El Congo", "La Amazonía”, "Irlanda" y el "Epílogo", despliega rápidamente todos los elementos transareales e histórico-móviles de relevancia, que hacen de El sueño del celta un texto de una importancia absoluta.

El sueño del celta es el sueño de un espacio global dentro del cual los diversos mundos puedan convivir, en mutuo respeto, pacíficamente y en diferencia. Es un sueño de la razón, pero que a la vez resulta también un sueño de la razón, en ese mismo sentido en el que lo pintó Francisco de Goya en su seguramente más famoso Capricho-simultáneamente un ensueño y una modorra de la razón: "El sueño de la razón produce monstruos". Del mismo

8 Sobre la epistemología de las redes en las ciencias sociales véase Latour y el volumen editado por Stegbauer.

Revista Iberoamericana, Vol. LXXXI, Núm. 253, Octubre-Diciembre 2015, 1115-1137 
modo, en la novela no se resuelve el hecho de si es el ensueño o la modorra de la razón la que produce los monstruos, la verdadera locura a escala global que la novela expone.

Pero, ¿cómo se ve el mundo globalizado del celta? Ya en el muy logrado diseño de portada de la novela realizado por Pep Carrió se hace visible, en el perfil recortado de Roger Casement, el protagonista de esta historia, ${ }^{9}$ un mapamundi, en el que los lugares de esta tercera etapa de la globalización acelerada en los que la acción sucede, aparecen como islas de un archipiélago global, conectadas entre sí mediante gotas de sangre. El Congo y la Amazonía están íntimamente enlazados, más bien encadenados, con Irlanda e Inglaterra.

La multifacética figura histórica de Roger Casement, nacido en 1864 cerca de Dublín y ajusticiado bajo el cargo de alta traición en Londres en 1916, vincula de este modo sus dos tan asimétricas islas de procedencia con los escenarios de aquella explotación colonial y neocolonial, a la cual estaban sometidos en ese momento el Congo y el Putumayo en la zona amazónica peruana. Es un mundo sumido en una despiadada política expansionista en la carrera de los poderes industriales por repartirse las "últimas" colonias, tal como eran cruda y paradigmáticamente consideradas en la Conferencia Africana celebrada en Berlín en 1884 -conferencia que será aludida varias veces en las acciones de la novela. Un mundo en la mira de muchos poderes coloniales antiguos, aunque también de algunos nuevos: un mundo que hace literariamente perceptible las condiciones específicas de la tercera fase de globalización acelerada, perspectivizada, por supuesto, transarealmente desde el trasfondo y los saberes del cuarto impulso globalizador de nuestros días. Ahora bien, ¿cómo permanece unido este mundo entre América, África y Europa?

Por lo pronto, puede sorprender un poco que describamos al paysage littéraire desplegado en El sueño del celta como un archipiélago. ${ }^{10} \mathrm{Si}$ los grandes ríos del Congo y del Amazonas nos señalan el hecho de que aquí por ningún motivo se trata de islas en un sentido geográfico, sino de grades continentes, dentro del transcurso de esta historia, inteligentemente orquestada por Vargas Llosa, aunque a veces con algunas repeticiones, se nos hace evidente que aquí lidiamos con islas en un sentido de la división del trabajo capitalista, en un sentido económico y, por lo tanto, global.

Ahora bien, las islas continentales se encuentran, tal como la isla geográfica de Irlanda frente a Inglaterra, en una situación de extrema dependencia y de falta de libertad ante los centros del mercado y de las políticas mundiales, que en el impulso globalizador del último tercio del siglo XIX propulsaron, despiadadamente y sin miramientos, la pérdida de innumerables vidas humanas en las colonias. Por medio de la explotación de los seres humanos por los seres humanos, la esclavitud continuada por la tercera fase, el mundo del

9 Sobre Casement desde una perspectiva de la literatura de viajes, véase Carr.

10 Sobre el uso de la figura del archipiélago para enfrentarse a problemas culturales de la zona andina y su ampliación transandina, ver las colaboraciones de Ulises Juan Zevallos Aguilar y Marco Thomas Bosshard en este volumen.

Revista Iberoamericana, Vol. LXXXI, Núm. 253, Octubre-Diciembre 2015, 1115-1137 
celta es un mundo en el que todos aquellos que se consideran parte de la "civilización" occidental -y con sólo muy pocas excepciones- perpetran los crímenes más terribles sobre aquellos seres humanos que son designados por ellos como "bárbaros".

El autor peruano escogió muy bien su tema y su objeto. En la figura del mismo Roger Casement, este condecorado diplomático británico, ascendido a la nobleza por sus servicios al Empire, pero también más tarde héroe nacional irlandés, rebelado en contra de Inglaterra, siempre culminan transarchipiélicamente los diferentes paisajes, asimetrías y formas de la explotación, que encadenan para bien o para mal y más allá de todas sus diferencias al Congo, la región del Putumayo y finalmente Irlanda. Mario Vargas Llosa en ningún caso nos presenta una simple historia de transferencias, en la cual, al principio y en el contexto de su civilización cristiana-occidental, el joven Roger Casement todavía parece creer. ¿No son acaso en última instancia los mismos intereses, las mismas fuerzas, las que sostienen todas las acciones políticas y económicas? ¿No hallamos al Congo por todos lados - tal como se repite varias veces en la novela-, de forma que las simples miradas entrecruzadas en una dimensión global parecen servir muy poco para la aclaración de estos procesos?

Toda la construcción de la novela no deja lugar a dudas: las regiones tropicales de África y América, a pesar de sus diferentes situaciones políticas - de un lado, una colonia belga, del otro el corrupto y económicamente dependiente Estado peruano-, se encuentran en una analogía estructural. Ambas son víctimas de las condiciones de una globalización acelerada, marcada por la competencia de los poderes por apropiarse las últimas colonias restantes. Ambas, tal como el caso de Inglaterra y su cercana Irlanda, se hallan vinculadas a Europa como islas dependientes y sometidas despiadadamente a sus intereses. ¿Cómo se podría hablar aquí con vistas al Perú, a pesar de toda la retórica nacionalista que se intercala en la novela, de un verdadero Estado nacional independiente?

La relacionalidad transareal creada en la tercera fase de la globalización acelerada vincula todo despiadadamente con sus jerarquías y asimetrías del poder. El sueño del celta intenta hacer esto evidente una y otra vez: el problema de Irlanda no podría comprenderse adecuadamente sin una comprensión de los mecanismos globales del dominio mundial británico. Y la Peruvian Amazon Company, con su Jefe Arana, muy respetado en los círculos financieros, no podría entenderse ni desde una perspectiva histórico-nacional peruana, ni desde una simple perspectiva global. En esta novela no se trata de una historia de transferencias, sea como sea que esta se manifieste, sino de una transareal historia de movimientos y mociones, cuya dinámica y cuya violencia son puestas estética e insistentemente en escena en este texto narrativo.

En esta competencia por ganancias, mercados y poder resultaba decisivo conseguir fuerzas laborales lo más baratas posibles, sin las cuales y sin su "libre" disponibilidad, jamás hubiera sido posible lograr la maximización de las ganancias pretendida por los consorcios que impulsaban la globalización. Desde una perspectiva histórico-global, por supuesto, perdemos rápidamente de vista las vidas de todos aquellos seres humanos que

Revista Iberoamericana, Vol. LXXXI, Núm. 253, Octubre-Diciembre 2015, 1115-1137 
en los contextos locales, regionales o nacionales son afectados directamente por estos desarrollos. En estos casos, discursos sobre los valores de occidente -quizás como lo hacían los representantes de la Peruvian Amazon Company- nublan el paisaje de una violencia tanto estructural-incorpórea como sangrienta-corporal, que en la novela de Vargas Llosa queda demostrada con toda su potencia narrativa.

Por lo mismo, no es simplemente un hecho anecdótico, sino que de una importancia estructural suma, que dentro de la misma novela distintas fases de la globalización acelerada se iluminen mutuamente entre sí y que pongan en duda sus continuidades. Esto sucede ya tempranamente en el transcurso de la novela, cuando el protagonista todavía cree en la misión civilizatoria de los europeos y se halla trabajando para la Sanford Exploring Expedition justamente en un lugar hasta el que "hace cuatrocientos años la carabela de Diego Cao" había llegado (Vargas Llosa 54). Y precisamente allí, donde antaño el navegante portugués había eternizado su nombre sobre una piedra -que entonces aún era legible-, una empresa de ingeniería alemana comenzaba la construcción de una ciudad para empleados coloniales, cuyas casas estaban confeccionadas de madera europea, aquí destinada sólo para uso de consorcios europeos. ¿Cómo podría comprenderse aquí un espacio, una casa, una ciudad desde una perspectiva fija y estática? ¿Cómo podría ingresar aquí una historia de los intercambios, cuando todo lo aparentemente estático sólo puede hacerse comprensible a partir de los movimientos de todos los objetos y de todos los testigos?

La continua inclusión de la primera fase de globalización acelerada, ${ }^{11}$ una fase ibérica -y en África principalmente portuguesa- no deja lugar a duda que El sueño del celta intenta comprender y hacer visible los procesos de la globalización como un fenómeno de longue durée, como un desarrollo que se extiende sobre varios siglos. Y esto no es ninguna hipótesis, sino una certeza: las literaturas del mundo no han comprendido jamás a la globalización -y con ello de manera distinta que las diversas disciplinas científicas que supuestamente debieran saberlo mejor-como un "nuevo" y singular fenómeno aparecido a principios del siglo XX. Los textos literarios reaccionan de forma verdaderamente sismográfica ante todos los movimientos que otros patrones de movimiento, en referencia a tránsitos anteriores, han guardado en sí mismos. Los estudios transareales no pueden renunciar a su saber polilógico - de hacerlo, esto redundaría sólo en su propio daño.

\section{LAS LITERATURAS DEL MUNDO Y LOS ESTUDIOS TRANSANDINOS}

Pero, ¿qué es lo que sabe, sobre qué nos informa y de qué es capaz la literatura? Una primera respuesta breve y concisa podría formularse quizás a lo mejor con un

11 Por ejemplo, otra referencia a la primera fase se encuentra en la página 73 de la edición citada de la novela de Vargas Llosa

Revista Iberoamericana, Vol. LXXXI, Núm. 253, Octubre-Diciembre 2015, 1115-1137 
giro algo paradójico: la literatura es, porque es más de lo que es. Porque en la literatura no prima la realidad representada que en ella debe desplegarse, sino principalmente la representación literaria de una realidad vivida. Es decir: la literatura apunta a la totalidad. En ella se trata de la vida (Ette, ZusammenLebensWissen 210-13).

Esto no significa que la literatura se reduzca a la vida ni que esté completamente separada de ella. La literatura no es pensable sin la vida. Desde hace milenios que ésta ha desarrollado una vida propia y así, un saber de la vida en la vida; un saber que en las culturas más diversas de este mundo y que en su históricamente mutable autonomía relativa ${ }^{12}$ no es sólo un saber de la vida desde sí misma, sino además se ha comprobado a la vez un saber de la vida en la vida para la vida (Ette, ÜberLebenswissen 19). Las literaturas del mundo constituyen de este modo a través de los milenios y a través de las culturas un excepcional receptáculo de saberes, que está en constante transformación, que mediante su integración en los más diversos fenómenos de producción, recepción y distribución es interactivo y que debido a esta capacidad de interactuar de las maneras más diversas, ha conservado una apertura y fluctuación fundamentales. De este modo, las literaturas del mundo tienen preparado un saber, el cual está siempre consciente de las fronteras de cada uno de sus propios saberes y, precisamente por eso, programado para el traspaso y superación de las fronteras de todo tipo.

A diferencia del concepto de la literatura mundial, que en el sentido de Goethe se opone vehementemente al de las literaturas nacionales (Ette, ZwischenWeltenSchreiben $27 \mathrm{~s}$ ), el concepto de las literaturas del mundo no puede pensarse de forma monológica ni simplemente dialógica (así como entre un "yo" y "los otros", entre una "civilización" y la "barbarie", entre el "occidente" y el "resto"): debe ser pensado fundamentalmente de manera polilógica.

El concepto mismo de la literatura mundial no es concebible sin la experiencia y la vivencia de la globalización; forma parte de aquellos conceptos compuestos con el adjetivo "mundial" que surgieron como reacción a la segunda fase de la globalización acelerada; piénsese simplemente en los conceptos de el "ciudadano mundial" (Weltbürger) o de la "historia mundial" (Weltgeschichte) surgidos entre los siglos XVIII y XIX. El concepto de la literatura mundial representa una respuesta a los desafíos que surgen a partir de las nacientes literaturas nacionales, aunque también a partir del impulso de globalización -por supuesto, aquella globalización que caracteriza el fin del siglo XVIII y no el fin del siglo XX. Su concepto se ha vuelto histórico, en el sentido que debe ser abierto a las problemáticas de los fenómenos de la globalización actuales en su historicidad: "la literatura mundial" requiere conceptualmente una traducción y reestructuración para nuestro presente y para nuestro futuro.

${ }_{12} \mathrm{Al}$ respecto se puede consultar el bello estudio sobre Pierre Bourdieu y su sociología del campo literario de Jurt.

Revista Iberoamericana, Vol. LXXXI, Núm. 253, Octubre-Diciembre 2015, 1115-1137 
Tal como lo hemos visto en los diferentes casos del Inca Garcilaso de la Vega y de Mario Vargas Llosa: este polilógico sistema de las literaturas del mundo no fue inventado desde un único lugar, no fue divulgado desde un único espacio, sino que cuenta con y dispone de las procedencias culturales y geográficas más diversas. Así surgen, en distintos espacios de movimientos y mociones y en distintos paisajes de nuestro planeta, formas y normas del saber de un saber (del) convivir, ${ }^{13}$ que en cuanto un saber de la vida tanto como un saber (del) sobre-vivir (ÜberLebensWissen) contienen y desarrollan también siempre un fundamental saber-del-con-vivir (ZusammenLebensWissen). Este saber de la vida nos es accesible a través de las culturas y través de los milenios e influye en las filiaciones más diversas de las literaturas actuales, tanto como de las venideras.

La problemática de la convivencia tratada a nivel del contenido por estas literaturas presenta a su vez -en el no menos multiforme nivel estructural- una convivencia de las lenguas, una convivencia de las lógicas, una convivencia de las culturas (ver Ette, Konvivenz). Una convivencia que debe confrontar siempre de manera renovada las formas y normas más diversas de la violencia.

La novela debut de Daniel Alarcón, Lost City Radio, publicada en 2007, nos revela impresionantemente cómo las literaturas del mundo no son solamente una representación de la violencia, sino una representación estética de la violencia vivida y vivenciada; que ellas no sólo narran sobre la violencia, sino que en su narración misma son ya una transformación productiva de la violencia vivida, vivenciada y también sobrevivida. Asesinatos y masacres, violencia y atrocidades son componentes de la convivencia, que dentro de las literaturas del mundo genera un saber (del) convivir y de sus fronteras, que cruza a las culturas y lenguas más diversas; un saber que una y otra vez nos demuestra literal y semióticamente que la tierra no puede pensarse a partir de una sola lógica, que la logósfera de nuestro planeta no está compuesta de una sola lengua y que el mundo no puede comprenderse a partir de una sola cultura o "civilización".

Si los paisajes en El sueño del celta de Mario Vargas Llosa podían vincularse a ciertos continentes claramente identificables, de cuya interacción archipiélica se desplegaba el paisaje transareal de la novela, en el caso de los paisajes de Lost City Radio, éstos no pueden ser identificados fácilmente con la realidad extralingüística. No es sólo que el autor de esta premiada novela, nacido en Lima en 1977 y que a los tres años se mudó con sus padres y cuatro hermanos a los Estados Unidos, declare en los agradecimientos que su libro no hubiera sido posible sin muchas historias de diversos narradores (259), sino además que Lost City Radio rehúye en las mismas acciones que representa cualquier asignación posible a una determinada guerra civil en una determinada región de este planeta (ver Ette, "Daniel Alarcón”).

13 Al respecto se pueden consultar los diversos ensayos del volúmen Wissensformen und Wissensnormen editado por mí.

Revista Iberoamericana, Vol. LXXXI, Núm. 253, Octubre-Diciembre 2015, 1115-1137 
A pesar de que la obra de Alarcón está principalmente escrita en inglés ${ }^{14}$ y que sin duda alguna puede ser considerada como una literatura sin residencia fija (ver Ette, ZwischenWeltenSchreiben), por supuesto que es posible especular, a partir del trasfondo biográfico y la procedencia peruana de este escritor, si esta novela, dividida en tres partes y en quince capítulos numerados consecutivamente, no se referirá en última instancia a la brutal guerra desatada por la guerrilla peruana Sendero Luminoso. Para esta lectura, es posible hallar numerosos indicios, sin embargo, no debemos desatender por ningún motivo el hecho que Lost City Radio rehúye cuidadosamente cualquier tipo de identificación del acontecer de la novela. No se trata entonces aquí de una guerra civil, sino por antonomasia de la guerra civil de la actualidad. Lost City Radio es una novela sobre la vida bajo las condiciones de la dictadura, la guerra y la violencia y no una representación novelística de una determinada realidad histórica que el texto nos ofrece de una manera codificada o en clave. Sus paisajes no son los paisajes andinos de Sendero Luminoso, sino los paisajes de la teoría que nos quieren evidenciar y hacer revivenciar sensiblemente una poliperspectiva y totalmente contradictoria teoría de una vertiginosa violencia y de una convivencia destruida. Todo aparece bajo el signo de una pérdida, que domina ya paratextualmente desde el título de esta novela escrita en inglés.

Las tácticas de la guerra descritas en Lost City Radio son observables tal cual o con modificaciones tanto en los Barbudos en torno a Fidel Castro como en los Tupamaros en el Río de la Plata, en los guerrilleros de la resistencia en los andes peruanos, en los revolucionarios en la jungla mesoamericana, incluso en los levantamientos civiles armados en África o en las guerras religiosas en Afganistán, Pakistán o en Irak (198). Aun cuando los nombres, las referencias geográficas generales o las remisiones a la población indígena en la jungla parezcan situar probablemente la diégesis de la novela en el continente americano, las posibilidades y procedimientos de la violenta lucha en contra de la brutal represión dictatorial están formuladas frecuentemente de manera tan parabólica, que éstas no apuntan a experiencias concretas en una guerra concreta, sino se dirigen de manera mucho más ambiciosa a la generalidad de una vida bajo el signo de la dictadura y la violencia. Así como en El sueño del celta de Mario Vargas Llosa, también en Lost City Radio de Daniel Alarcón se traslapan los paisajes en un contexto fundamentalmente transtrópico.

Las contextualizaciones históricas de ambas novelas son por supuesto radicalmente diferentes, a pesar de que en Lost City Radio aparezcan, una y otra vez, continuidades transhistóricas. Cualquiera puede ser víctima en esta periódicamente atizada guerra civil, dentro de la cual, desde la perspectiva de la guerra entre Estados, no existen "distinciones

$14 \mathrm{Su}$ volumen de cuentos publicado en 2006, War by Candlelight, está escrito en inglés. Sin embargo, Daniel Alarcón es también coeditor de la revista Etiqueta Negra, publicada en Lima. Véase también al respecto mi entrevista con el autor (Ette, "La transmutación").

Revista Iberoamericana, Vol. LXXXI, Núm. 253, Octubre-Diciembre 2015, 1115-1137 ISSN 0034-9631 (Impreso) 
entre combatientes y no combatientes" (Münkler 8). Nadie está fuera de este conflicto, que para los habitantes de los países afectados ya parece ser casi un suceso natural. Y aun así todo está potenciado por la mano humana: una prepotencia inhumana.

En Lost City Radio, los civiles son presa de los ataques de la represión total del lado de la dictadura militar dominante, tanto como de los ataques dirigidos o del terror difuso por el lado de los revolucionarios de la Illegitimate Legion. Casi todas las figuras de la novela son simultáneamente sujetos $y$ objetos de la acción, victimarios $y$ víctimas: Lost City Radio no presenta ninguna categoría simple, ninguna distinción entre el bien y el mal, ninguna solución sencilla. El mundo creado por Daniel Alarcón despliega un paisaje polilógico, presenta muchas historias, perspectivas, discursos y lógicas. Es un paisaje de la violencia petrificado en los horrores omnipresentes -y aun así en movimiento constante.

En este país, desgarrado por estas largas y duraderas guerras civiles y en el cual ya sólo existe una historia oficial y en el que todas las otras historias, las vidas de los otros, han sido suprimidas; en este país sólo existe, como instancia unificadora, la suave y emotiva voz de la radiolocutora Norma, quien en su programa oye y da voz a aquellos que la llaman. Los nombres de los desaparecidos pueden ser nombrados a partir de listas (Listen) censuradas por el Estado: artilugios (Listen) de un Estado, que busca una salida fácilmente controlable para los lastres de los ciudadanos sometidos por él.

En el momento en que la voz de esta madre de la nación se hace audible, una desgarrada y reprimida nación se sienta de inmediato frente a los aparatos de radio; da igual si es en las innominadas poblaciones en la jungla o en los bloques habitacionales dentro de la innominada ciudad, todos aguardan a Norma: "Norma, to listen and heal them; Norma, mother to them all" (21). Como madre de esta nación, como encarnación de una compasiva matria que emerge contrapuesta a la represiva patria que vigila todos los espacios de la vida social e individual, crea Norma al menos un espacio acústico para los sufrimientos; pero también encarna simultáneamente la normalización del estado de excepción, en total correspondencia con lo que advierte Giorgio Agamben, sobre la progresiva perpetuación del stato di eccezione en las sociedades occidentales del siglo XX.

Por lo mismo, sería una reducción considerar a Norma como una figura de resistencia unidimensional y comprender a "Lost City Radio" como un inequívoco programa radial subversivo. ${ }^{15}$ Con el sólo hecho de referir la normalización vinculada a su voz y a su nombre, se hace posible explicar por qué el programa de Norma, a pesar de ser siempre controlado, a final de cuentas no sólo es tolerado, sino además promovido: Norma es responsable de los altos índices de audiencia y de la más alta venta de minutos publicitarios,

${ }_{15}$ Este tipo de interpretaciones se encuentran sobre todo en reseñas al libro en el espacio de habla alemana, como por ejemplo Tröger, Beate: "Die Verschwundenen im Äther". Frankfurter Allgemeine Zeitung 30 oct. 2008. Innumerables estereotipos de la imagen de América Latina se encuentran en la reseña de Löffler, Sigrid: "Eine Liebe in Zeiten des Bürgerkriegs", disponible en: <http://www.dradio.de/dkultur/ sendungen/kritik/840808> (2008).

Revista Iberoamericana, Vol. LXXXI, Núm. 253, Octubre-Diciembre 2015, 1115-1137 
algo que su jefe, Elmer, quien tal vez aún sigue enamorado de ella, sabe apreciar muy bien. El programa es parte de una normalización (de la vida y de las condiciones) de la dictadura - y desde esta perspectiva, Norma es un componente de este paisaje mediático controlado por el Estado. Las listas (Listen) de los desaparecidos se transforman en los artilugios (Listen) de una dictadura, que detrás de la voz de Norma, quien en otros días lee las noticias editadas por los militares, puede ocultar hábilmente su rostro. Y la vida de Norma se ha vuelto, antes de que comience a extrañar su propia vida en la lectura de la vida de los desaparecidos, la vida de los otros, la vida de una otra.

Ya en el tercer capítulo de la novela de Daniel Alarcón nos enteramos que la historia del país es una historia de constantes guerras de guerrillas, en la que no se abren nuevos horizontes por ninguna parte:

The country's history was dotted with guerrilla episodes of varying intensities: here and there, a ragtag militia fired by an empty ideology or a provincial grievance, a lightly armed band led by a quixotic upper-crust dropout - it happened all the time, twice a generation, and ended the same way: the insurgents marched themselves to starvation, were felled by malarial fevers. They played at war on the fringes of the nation-state, then gave up as soon as the shooting began. (46)

Con respecto a la IL, la Illegitimate Legion, la diferencia radicaba sólo en que ésta no se había dado por vencida tan fácilmente, desencadenando así una larga, encarnizada y sangrienta guerra civil, que había terminado una vez más, luego de un extremadamente alto número de víctimas, en especial dentro de la población civil, en una derrota de los rebeldes. Las diversas historias de estas rebeliones, las historias de estas guerras y guerrillas, que con relativa regularidad ocurrían cada dos generaciones, constituyen sin embargo -así se puede decir con razón- la verdadera historia del Estado nacional: ellas forman el andamiaje narrativo de innumerables historias, de las cuales la historia nacional se ha forjado. Una historia de las luchas, no una de la convivencia exitosa.

La guerra, que en la novela debut de DanielAlarcón es todas las guerras, ha producido historias que bajo el signo de la dictadura reclaman otras formas de expresión; precisamente con miras a sus puntos de partida, a sus finales, estas historias vitales deben ser narradas, para no desaparecer para siempre. De ahí la importancia de los nombres registrados en aquellas largas listas: para garantizar en cada caso un mundo completo de historias propias -y con ello garantizar también la supervivencia misma después de la aniquilación y la desaparición. Una nación completa construida en base a las listas de desaparecidos, a partir de los nombres de las víctimas de la exclusión, quienes sólo pueden hacerse presentes en su ausencia- una generación perdida, una ciudad perdida: Lost City.

En estas historias, la vida de los otros se hace vívida, sobrevive en el proceso de la narración, aunque permite sobre todo proyectar otra vida, cuyas historias son vitales para el yo, para una supervivencia dentro de una nación, en la que los nombres se reemplazan

Revista Iberoamericana, Vol. LXXXI, Núm. 253, Octubre-Diciembre 2015, 1115-1137 
por números. Así, la disponibilidad de historias que ofrece el programa radial de Norma, gracias a los que llaman y cuentan una y otra vez fragmentos de nuevas historias, se transforma en un generador medial de un saber (del) sobre-vivir, dentro del cual lo perdido puede volver a vivir: City Radio.

De esta manera surge medialmente una nación, cuyo carácter de constructo ya no puede engañar ni encubrir más el hecho de que precisamente en la exclusión de los otros, precisamente en su obstinación en lo territorial, crea un espacio vectorial, que resulta paradigmático para otras guerras civiles, otras naciones, otras tiranías. Aquí nos enfrentamos a una modelización transareal, que desde un país, desde un lugar sopesa el campo de fuerzas de la tierra.

En la medida en que Norma trae al oído la vida de los otros -en el núcleo narrativo de los nombres, que guardan siempre nuevos nombres-, es que ella abre en su tan querido programa "Lost City Radio" aquel acústico espacio de eco que hace posible la reflexión sobre las respectivas historias propias -y lógicamente también para la propia historia de vida de Norma, quien ya casi se había acostumbrado completamente a la desaparición de Rey, su esposo. La fuerte medida en que este programa dominical no sólo es censurado y controlado, sino además ritualizado, puede revelarnos algo de la función cuasi-religiosa de esta fabulación radial extendida por toda la nación, aunque sobre todo nos ilumina el hecho de que Norma se ha vuelto para los escuchas de su programa radial una especie de ser venerado como una santa, cuyas ropas son tocadas, porque prometen protección para la propia vida y la propia supervivencia. Las historias de los otros y la vida de los otros se encarnan en ella, adquieren su voz, y su forma. Y así, tal como la nación necesita de las otras naciones para su construcción, la vida de Norma también requiere aquellas historias de la vida de los otros, de la vida de su hace ya largo tiempo asesinado esposo Rey, para demarcar el espacio de lo propio, que es siempre ya un espacio de lo otro.

En esta transformación de la vida de los otros en un sinnúmero de historias que se atraviesan mutuamente, posibilitada a través de la tecnología radial, se crea un fructífero y colectivo saber sobrevivir dentro de una dictadura "normalizada", para el cual la oposición entre "realidad" y "ficción" se vuelve cada vez más inoperante. Durante la semana, Norma lee las noticias como locutora profesional, lo que al menos le permite dar un tono agridulce y siempre esperanzador a las horribles "informaciones" y noticias, cuya procedencia tanto como su estatus Norma conoce bien:

It was the only national radio station left since the war ended. After the IL was defeated, the journalists were imprisoned. Many of her colleagues wound up in prison, or worse. They were taken to the Moon, some were disappeared, and their names, like her husband's, were forbidden. Each morning, Norma read fictitious, governmentapproved news; each afternoon, she submitted the next day's proposed headlines for approval by the censor. These represented, in the scheme of things, very small humiliations. The world can't be changed, and so Norma held out for Sunday. [...]

Revista Iberoamericana, Vol. LXXXI, Núm. 253, Octubre-Diciembre 2015, 1115-1137 
The IL was defeated and disgraced; the country was now in the process of forgetting that the war ever happened at all. (10)

Mediante el ejemplo de una guerra civil, Lost City Radio de Daniel Alarcón nos muestra el programa y la programática de una literatura que se aboca a la guerra civil, al desarrollo de preguntas fundamentales sobre la vida, sobre el saber de la vida y sobre el saber-sobre-el-con-vivir. La construcción de la nación a partir de la exclusión así como las lógicas del otro y las otras lógicas llevan al colapso de lo nacional, que en su novela se representa como una historia y como una historia de luchas, cuya única meta es combatir sin fin hasta la imposición de la propia lógica, la propia razón y la propia razón de Estado. ¿Es acaso esta nación el Perú, el país de nacimiento del autor? La respuesta a esta pregunta, que en última instancia aspira a una fijación territorial del tema, me parece mucho menos reveladora que responder a la pregunta de si -y si es así, por qué y cómoes posible afiliar la novela de Daniel Alarcón también a la literatura peruana, más allá de su pertenencia a las literaturas sin residencia fija.

Si la literatura nos permite pensar simultáneamente en diversas lógicas, entonces también nos entrega a la vez la llave para proteger nuestra vida del dominio de una sola lógica, de una sola escritura de la historia. Con Daniel Alarcón nos topamos en la cuarta fase de la globalización acelerada con una literatura peruana que, de cara a sus fracasos, deja atrás de sí los modelos nacionales y que continúa escribiendo, a partir del espacio de movimientos de las literaturas del mundo, una literatura peruana desde la perspectiva de las literaturas sin residencia fija. Una atribución de este tipo incluye también las actividades de Alarcón dentro del campo literario peruano ya mencionadas, sin embargo no las establece como condición necesaria. Desde la perspectiva aquí escogida, podríamos designar a la literatura de Alarcón como una literatura transareal, transandina peruana, que se mueve tanto dentro del campo magnético literario de los Estados Unidos como del Perú, aunque también desde un sentido transareal se encuentra en constante oscilación entre diversas "pertenencias". Sólo con violencia sería posible reducirla a una sola de éstas.

Ahora bien, aquí hay mucho más en juego. Ya que esta dimensión de la escritura transandina radicalizada en la cuarta fase de la globalización acelerada por ningún motivo despliega su potencial sólo desde una pretendida distancia espacial, sino más bien a partir del espacio de juego que se da en la escritura en lengua inglesa. ¿Pero puede haber una literatura peruana escrita en lengua inglesa?

Sin desistir absolutamente del castellano como forma de expresión literaria, Daniel Alarcón inscribe el horizonte transandino de su literatura en una dimensión translingual, dentro de la cual el recurso al inglés conlleva una enriquecedora amplificación de aquello que bajo las condiciones de la globalización actual podemos comprender como literatura peruana. La vectoricidad de lo translingual que cruza las distintas lenguas hace posible oír las lenguas de los otros en la propia lengua de manera impresionante y con ello

Revista Iberoamericana, Vol. LXXXI, Núm. 253, Octubre-Diciembre 2015, 1115-1137 
pensar a la vez lo otro en lo propio, aunque sin eliminar lo otro en su diferencia. ${ }^{16}$ Esto no es otra cosa que el intento de pensar conceptualmente la compleja relacionalidad de las literaturas del mundo - y su capacidad para traspasar las fornteras -, de tal forma que los mecanismos de exclusión de las hasta ahora prepotentes literaturas nacionales no nos bloqueen más la mirada de la polilógica de la literatura.

Así se inauguran nuevos espacios de pensamiento vectoriales, que permiten desplegar aquellos espacios de juego globales que las literaturas del mundo amplifican una y otra vez de manera renovada. A la luz de los estudios transandinos, lo nacional se revela parte de una historia móvil y de movimientos mucho más amplia, tal como las literaturas del mundo, desde hace tiempo, nos lo evidencian de manera fascinante. Una historia espacial desde hace ya tiempo que no le hace justicia a su saber polilógico y poliperspectivístico.

Ante este trasfondo se despliegan también, y precisamente en la literatura peruana, aquellas fuerzas vectoriales, que con la ayuda de las literaturas del mundo nos permiten imaginar, pensar, leer y vivir el origen como procedencias y el futuro como porvenires. Los estudios transandinos inauguran así dentro del contexto de los TransArea Studies la valiosa y vital posibilidad de desplegar, a partir de movimientos polilógicos, a partir de perspectivas polilinguales y con la fuerza prospectiva de la literatura, un pensamiento de lo venidero y de la vida futura en paisajes globales. Una filo-poli-logía está comprometida con esta fuerza, abierta y prospectiva, de las literaturas del mundo.

Traducción: Vicente Bernaschina Schürmann

\section{BiBLIOGRAFÍA}

Agamben, Giorgio. Stato di eccezione. Homo sacer, II, 1. Torino: Bollati Boringhieri, 2003.

Alarcón, Daniel. Lost City Radio. 2007. London-New York-Toronto: Harper Perennial, 2008.

Appadurai, Arjun. Modernity at Large. Cultural Dimensions of Globalization. Minneapolis/London: U of Minnesota P, 1996.

Brading, David A. "The Incas and the Renaissance: The Royal Commentaries of Inca Garcilaso de la Vega". Journal of Latin American Studies 17/1 (1986): 1-23.

Carr, Helen. "Roger Casement in the Amazon, the Congo, and Ireland". Writing Travel, and Empire. In the Margins of Anthropology. Peter Hulme y Russell McDougall, eds. London/New York: I.B. Tauris, 2007. 169-94.

${ }^{16}$ Dos indagaciones que destacan dimensiones translinguales en obras literarias producidas en distintas épocas y con distintos intereses la zona andina, se encuentran en las colaboraciones de Vicente Bernaschina Schürmann y Elizabeth Monasterios en este volumen.

Revista Iberoamericana, Vol. LXXXI, Núm. 253, Octubre-Diciembre 2015, 1115-1137 
Cramer, Friedrich. Chaos und Ordnung. Die komplexe Struktur des Lebendigen. Frankfurt am Main/Leipzig: Insel Verlag, 1996.

Ette, Ottmar. “DanielAlarcón, 'Lost City Radio': Vom Krieg, den Sprachen der Diktatur und der Erfindung eines anderen Lebens". Sprachkontakte, Sprachvariation und Sprachwandel. Festschrift für Thomas Stehl zum 60. Geburtstag. Claudia Schlaak y Lena Busse, eds. Tübingen: Narr Verlag, 2011. 485-502.

Konvivenz. Literatur und Leben nach dem Paradies. Berlin: Kulturverlag Kadmos, 2012.

Literatur in Bewegung. Raum und Dynamik grenzüberschreitenden Schreibens in Europa und Amerika. Weilerswist: Velbrück Wissenschaft, 2002.

TransArea. Eine literarische Globalisierungsgeschichte. Berlin/Boston: Walter de Gruyter, 2012.

"La transmutación de culturas". Entrevista a Daniel Alarcón, ganador del Premio Internacional de Literatura de la Casa de las Culturas del Mundo. Iberoamericana 19/37 (2010): 157-180.

ÜberLebenswissen. Die Aufgabe der Philologie. Berlin: Kulturverlag Kadmos, 2004.

ZusammenLebensWissen. List, Last und Lust literarischer Konvivenz im globalen Maßstab (ÜberLebenswissen III). Berlin: Kulturverlag Kadmos, 2010.

ZwischenWeltenSchreiben. Literaturen ohne festen Wohnsitz (ÜberLebenswissen

II). Berlin: Kulturverlag Kadmos, 2005.

ed. Wissensformen und Wissensnormen des ZusammenLebens. Literatur-KulturGeschichte-Medien. Berlin/Boston: Walter de Gruyter, 2012.

Ferguson, Niall. Civilization. The West and the Rest. New York: Penguin Books, 2011.

Fritz, Sabine. "Reclamar el derecho a hablar. El poder de la traducción en las crónicas de Guamán Poma de Ayala y del Inca Garcilaso de la Vega". Traducción y poder. Sobre marginados, infieles, hermeneutas y exiliados. Liliana Ruth Feierstein y Vera Elisabeth Gerling, eds. Frankfurt am Main/Madrid: Iberoamericana/Vervuert, 2008. 101-20.

Garcilaso de la Vega, el Inca. Comentarios reales de los Incas. 2 Vol. Prólogo, edición y cronología Aurelio Miró Quesada. Caracas: Biblioteca Ayacucho, 1985.

González Acosta, Alejandro. "Dos visiones de la integración americana: 'Comentarios reales' del Inca Garcilaso de la Vega y 'Crónica mexicana' de Fernando Alvarado Tezozómoc". America Latina. Historia y destino. Homenaje a Leopoldo Zea. Tomo III. 3 vol. México: Universidad nacional Autónoma de México, 1993. 49-62. Gruzinski, Serge. "Les mondes mêlés de la Monarchie catholique et autres 'connected histories". Annales (2001): 85-117.

Hilton, Sylvia L. Garcilaso de la Vega, el Inca. "Introducción”. La Florida del Inca. Madrid: Historia 16, 1996. 7-52.

Revista Iberoamericana, Vol. LXXXI, Núm. 253, Octubre-Diciembre 2015, 1115-1137 
Huntington, Samuel P. The Clash of Civilizations and the Remaking of World Order. New York-London-Toronto-Sydney: Simon \& Schuster, 1996.

Iniesta Cámara, Amalia. "Inca Garcilaso de la Vega y José Carlos Mariátegui: dos fundadores de la peruanidad". Revista del Centro de Letras Hispanoamericanas 6-8 (1996): 149-60.

Jakfalvi-Leiva, Susana. Traducción, escritura y violencia colonizadora: un estudio de la obra del Inca Garcilaso. Syracuse: Maxwell School of Citizenship and Public Affairs, 1984.

Jurt, Joseph. Das literarische Feld. Das Konzept Pierre Bourdieus in Theorie und Praxis. Darmstadt: Wissenschaftliche Buchgesellschaft, 1995.

Latour, Bruno. Eine neue Soziologie für eine neue Gesellschaft. Einführung in die Akteur-Netzwerk-Theorie. Aus dem Englischen von Gustav Roßler. Frankfurt am Main: Suhrkamp, 2007.

Lavalle, Bernard. "El Inca Garcilaso de la Vega". Historia de la Literatura Hispanoamericana. Tomo. I: Epoca colonial. Luis Iñigo Madrigal, ed. Madrid: Ediciones Cátedra, 1982. 135-43. 3 Vol.

López-Baralt, Mercedes. El Inca Garcilaso: traductor de culturas. Madrid/Frankfurt am Main: Iberoamericana/Vervuert, 2011.

MacCormack, Sabine. "The Incas and Rome". Inca Garcilaso de la Vega: An American Humanist. A Tribute to José Durand. José Anadón, ed. Notre Dame: U of Notre Dame P, 1998. 8-31.

On the Wings of Time: Rome, the Incas, Spain, and Peru. Princeton: Princeton UP, 2007.

"Religion and Philosophy: Garcilaso de la Vega and some Peruvian readers, 1609-1639." Religion in the Andes: Vision and Imagination in Early Colonial Peru. Princeton: Princeton UP, 1991. 332-82.

Mataix, Remedios. "Inca Garcilaso de la Vega: apunte biográfico". Biblioteca virtual Miguel de Cervantes, Biblioteca Americana, Inca Garcilaso de la Vega. < http://www. cervantesvirtual.com/bib_autor/incagarcilaso/pcuartonivel.jsp?conten=autor $>.18$ marzo 2013.

Mazzotti, Juan Antonio. Coros mestizos del Inca Garcilaso: resonancias andinas. México: Fondo de Cultura Económica, 1996.

Mitchell, W.J.T. Landscape and Power. Second edition. Chicago/London: The U of Chicago P, 2002.

Montiel, Edgar. "El Inca Garcilaso y la independencia de las Américas". Cuadernos Americanos 131 (2010): 113-32.

Münkler, Herfried. "Geleitwort”. Bürgerkrieg. Erfahrung und Repräsentation. Isabella von Treskow y otros, eds. Con un Prefacio de Herfried Münkler. Berlin: trafo Verlag, 2005. 7-12.

Revista Iberoamericana, Vol. LXXXI, Núm. 253, Octubre-Diciembre 2015, 1115-1137 
No, Song. "La oralidad garcilasista en los Comentarios reales de los Incas". Perspectivas Latinoamericanas 3 (2006): 161-72.

Quilter, Jeffrey y Gary Urton, eds. Narrative Threads: Accounting and Recounting in Andean Khipu. Austin: U of Texas P, 2002.

Randeria, Shalini. "Geteilte Geschichte und verwobene Moderne”. Zukunftsentwürfe. Ideen für eine Kultur der Veränderung. Jörn Rüsen y otros, eds. Frankfurt am Main: Campus, 1999. 87-94.

Sánchez, Luis Alberto. "La literatura en el Virreynato". Historia del Perú. Tomo V: Perú colonial. 12 vol. Juan Mejía Baca, ed. Lima: Editorial Mejía Baca, 1980.

Scharlau, Birgit. “Abhängigkeit und Autonomie. Die Sprachbetrachtungen von Inca Garcilaso de la Vega". Iberoamericana 25-26 (1985): 53-64.

Sempat Assadourian, Carlos. "Narrative Accounting and Memory According to the Colonial Sources". Narrative Threads: Accounting and Recounting in Andean Khipu. Jeffrey Quilter y Gary Urton, ed. Austin: U of Texas P, 2002. 119-50.

Stegbauer, Christian, ed. Netzwerkanalyse und Netzwerktheorie. Ein neues Paradigma in den Sozialwissenschaften. Wiesbaden: VS Verlag für Sozialwissenschaften, 2010.

Subrahmanyam, Sanjay. "Connected Histories: Toward a Reconfiguration of Early Modern Eurasia”. Modern Asian Studies 31/3 (1997): 735-62.

Urton, Gary. "Recording Signs in Narrative-Accounting Khipu". Narrative Threads: Accounting and Recounting in Andean Khipu. Jeffrey Quilter y Gary Urton, ed. Austin: U of Texas P, 2002. 171-96.

Vargas Llosa, Mario. El sueño del celta. México: Santillana-Alfaguara, 2010.

Werner, Michael y Bénédicte Zimmermann. "Vergleich, Transfer, Verflechtung. Der Ansatz der 'Histoire croisée' und die Herausforderung des Transnationalen". Geschichte und Gesellschaft 28 (2002): 607-36.

Zamora, Margarita. Languages, Authority, and Indigenous History in the Comentarios reales de los Incas. Cambridge: Cambridge UP, 1988. 
